\title{
Mechanical behavior of RC exterior wide beam-column joints under lateral loading: a parametric computational study
}

\author{
Elahe Etemadi ${ }^{* 1}$, Thomas Vincent ${ }^{\# 2}$ \\ * Department of Civil Engineering, Semnan University, Semnan, Iran \\ ${ }^{1}$ E.etemadi.khosroshahi@gmail.com \\ ${ }^{\#}$ Faculty of Science and Engineering, School of Computer Science, \\ Engineering and Mathematics, Flinders University, Adelaide, Australia \\ ${ }^{2}$ thomas.vincent@flinders.edu.au
}

\begin{abstract}
A computational investigation was conducted using finite element model to evaluate the influence of geometric parameters on the behavior of exterior wide beam-column connections for reinforced concrete (RC) members under $5 \%$ lateral drift. After accurately verifying this model against existing experimentally recorded data, the force-displacement curves were determined for various dimensions of wide beam-column joints. The influence of dimension variation for wide beam on ductility, strength and energy dissipation of the exterior joint was quantitatively evaluated. The results demonstrated that the amount and configuration of steel reinforcement has significant influence on behavior of wide beam-column connections. For widths ranging from 600 to $1000 \mathrm{~mm}$, an increase in width can result in up to $36 \%$ reduction in ductility, $36 \%$ strength enhancement and $33 \%$ increase in energy dissipation. In addition to this, the effect of axial load on strength of structures was studied and the results showed that for the axial load increase from 150 to $350 \mathrm{kN}$ resulted in a $30 \%$ reduction in strength.
\end{abstract}

Keywords: Reinforced concrete, wide beam, beam-column connection, finite element model.

\section{INTRODUCTION}

One of the most useful structures in civil engineering for resisting against lateral loading is moment frame system. It is clear that beam-column connections are the most critical parts in the moment frame systems, as they tolerate maximum loads and moments, under lateral loading. Wide beam-column joints are one of several types of reinforced concrete (RC) connections that are being used in these frame systems and it has many advantages such as decreasing the time and cost of construction processes. These merits have led to the development of several studies to evaluate the behavior of this connection [1]. Despite its advantages, there are some performance limitations such as low capacity to absorb energy which restricts the application of this connection type in locations with seismic activity $[2,3]$. However, some researchers have suggested that improving the details of these connections can enable the use of them in seismic regions without limitation $[4,5]$. Previous research into wide beam-column connections includes experimental tests that were carried out to understand and improve lateral sway behavior. Russell Gentry and Wight conducted an experimental test by using $850 \mathrm{~mm}$ wide beam-column joints in high seismic areas and concluded that the transfer of plastic hinge bending moment to the column should be taken into account to prevent transverse beam damage by cracking due to torsional moments [6]. Li and Kulkarni investigated $800 \mathrm{~mm}$ wide beams experimentally and numerically, where it was found that reinforcement ratio in the column-to-beam connection has significant effect on behavior of these connections [2,9]. LaFave and Wight evaluated three exterior reinforced concrete wide beam-column joints according to the American Concrete Institute provisions under lateral quasi static loading and concluded that the strength of these joints when resisting against torsional moment is similar to conventional joints $[7,8]$. Elsouri and Harajli conducted an experimental test on four interior wide beam-column connections, with 800 $\mathrm{mm}$ wide beams and 200 by $650 \mathrm{~mm}$ columns, to assess the behavior of RC wide beam-narrow column under seismic loading. The results revealed that by improving reinforcement detailing, behavior of joints dramatically improved [11]. Elsouri et al. investigated seismic behavior of exterior wide beam-column joints by using two full scale gravity-load designed specimens under quasi static cyclic loading and two more joints considered "earthquake resistant". They concluded that the detail of reinforcements can significantly increase seismic resistance by delaying shear failure in joints [10]. A study was carried out by Dominguez et al. on one slab with wide beam-column joints under the 2011 Lorca earthquake loading of magnitude 5.1 in Spain. They concluded that buildings designed without any seismic provisions did not survive Lorca earthquake loading, even in low seismicity areas. While, other buildings that had met seismic requirements, survived under higher seismic loadings [12]. An experimental study was carried out by Fernando et al. to investigate European code provisions about behavior of wide beam-column connections. It was revealed that by applying these provisions the behavior of wide beam joints was similar to conventional joints under the same lateral loading [13]. Another 
investigation was conducted by Mirzabagheri et al. on two conventional joints and two joints with wide beam. The results demonstrated that the shear strength of the wide beam-column joints was sufficient while it was not sufficient for conventional beam-column connections. Additionally the energy dissipation was the same for all specimens [14].

Some analytical research has also been conducted to evaluate the behavior of connections especially in wide beam-column joints areas. An analytical study was carried out by Rodriguez et al. in beam-column connections to investigate the effect of bond deterioration between bars and concrete [15]. To estimate the displacements of several types of beams, especially wide beams, a method that is called the indirect displacement estimation using acceleration and strain (IDEAS) was developed by Cho et al. [16]. A study conducted by Unal and Burak produced models for predicting the influence of a variety of parameters such as eccentricity and transverse beams on the seismic behavior of the beam-column joint [17].

Using finite element (FE) model is one of the most convenient and practical analytical methods to evaluate the behavior of structures. Limitations of experimental tests, such as the high financial costs for full scale tests and the time constrains for preparation of complex geometry and load applications, can be solved by using finite element simulations [18-21]. Moreover, a key parameter which can influence the behavior of connections under lateral loading, is the axial load being applied to the column. A number of research studies have been performed to investigate the effect of this parameter on the column-to-beam joint behavior. An investigation performed by Kitayama et al. [22] cited that an axial load smaller than $0.5 f_{c} A_{g}$, where $f_{c}$ is compressive strength of concrete and $A_{g}$ is gross area of RC column section, does not have significant effect on shear strength of connection. Bing $\mathrm{Li}$ and Kukarni [2] studied the effect of axial load on shear strength by investigating axial loads in the range of $0.1 f_{c} A_{g}$ to $0.4 f_{c} A_{g}$. They conclude that when the axial load increased to $0.2 f_{c} A_{g}$ and $0.25 f_{c} A_{g}$, shear strength of models enhanced, whereas for loads above $0.25 f_{c} A_{g}$ the shear strength decreased. However no study to date has examined the influence of beam width variations and amount of axial loads smaller than $0.1 f_{c} A_{g}$, on behavior of exterior wide beam-column connections under lateral displacement.

To investigate the influence of dimension variation and load application on the behavior of RC wide beamcolumn connections, this study selected a numerical investigation to evaluate the behavior of exterior wide beam-column connection specimen (EWBCC) under lateral loading. This model was verified by experimental results reported from test carried out by Fadwa et al. [3]. The influence of the geometric parameters on ductility and strength of the exterior joint was quantitatively evaluated. In addition to this, dissipated energy and the impact of axial load on the wide beam-column connections were investigated.

\section{Methodology}

A parametric study was performed to quantitatively investigate the influence of beam width variation on the behavior of the exterior wide beam-column joint. ABAQUS/CAE software was used to model a EWBCC specimen with the same details as those experimentally tested in Fadwa et al. [3]. According to the experimental test, an exterior wide beam with cross-section of 900 by $300 \mathrm{~mm}$ and column with cross section of 400 by 450 $\mathrm{mm}$, were used. Figure 1 shows the details and the locations of the reinforcements of this joint which are identical to Fadwa et al.'s specimens. As is shown in Figure 1, 4 of the 7 longitudinal reinforcing bars in the beam are located outside the column core. Additionally, 4 and 6 bars with diameters of $16 \mathrm{~mm}$ were used at the top and bottom of the column core respectively, to represent the transverse beams reinforcing bars. The transverse bars help to confine and improve the joint's behavior. In the numerical setup, the beam ends had vertical constraints and the bottom of the column was pinned, to match the test setup of Fadwa et al.'s experimental research.

Table 1 shows the geometric characteristics of different specimens where the column and beam reinforcement details have been reported in this study, the models have been labelled by the letters BW which relate to the beam width. For instance BW600 is a wide beam-column connection where the width of beam is $600 \mathrm{~mm}$. In this study the beam width is the key parameter and it varies from 600 to $1000 \mathrm{~mm}$. As is presented in Table 1, longitudinal reinforcement bars are also a key parameter and their amount is either 2 or 4 and 5 or 7 for bottom and top of the beam respectively, with wide beams receiving more reinforcing bars. The dimensions for the column cross section are 400 by $450 \mathrm{~mm}$ and the height of the beam is $300 \mathrm{~mm}$ for all models. 

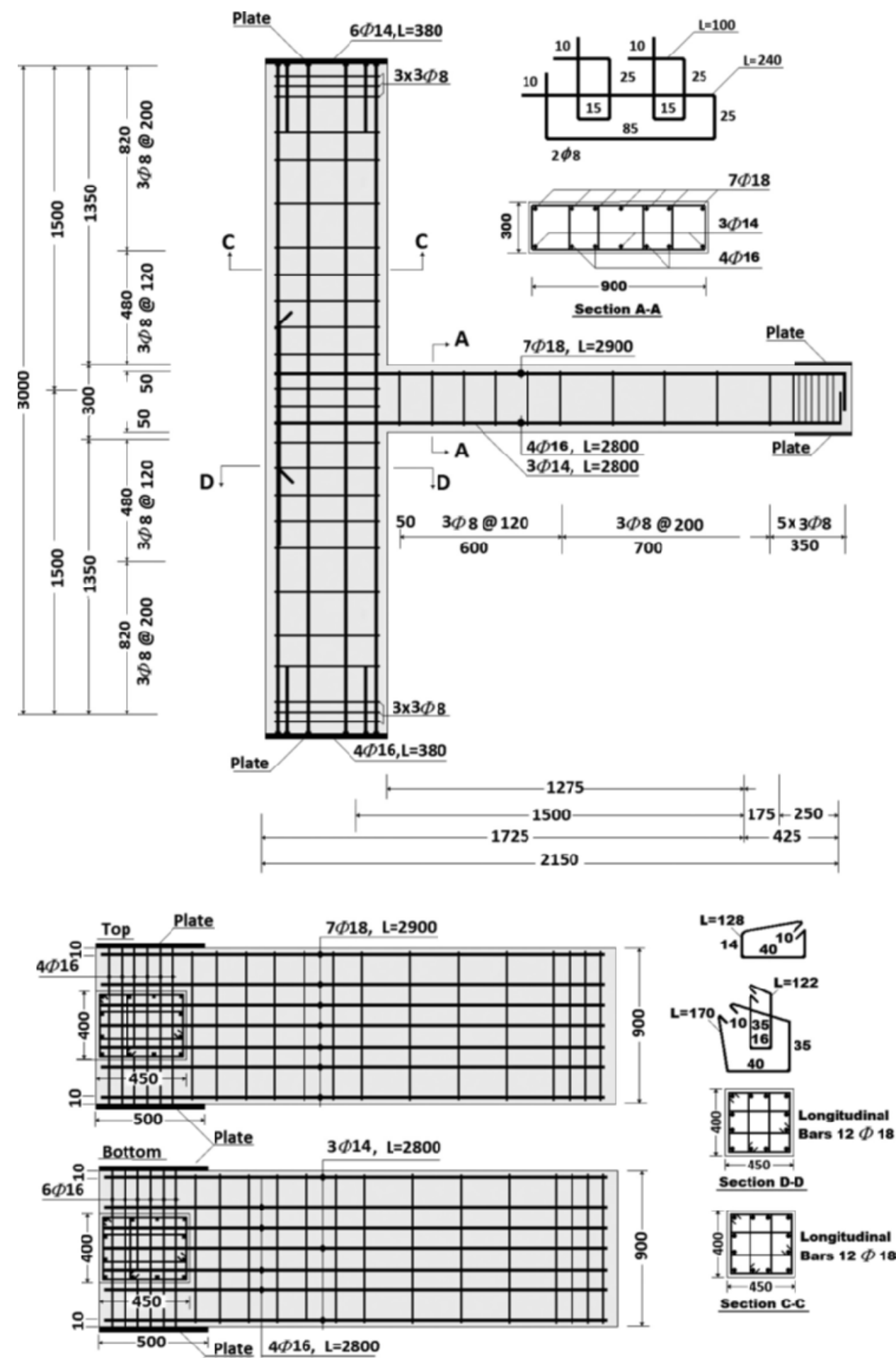

Fig.1. Reinforcement and dimension details of experimental test [3]

TABLE I. Reinforcing Bar Detailing

\begin{tabular}{|l|l|l|l|l|}
\hline \multirow{2}{*}{ Row } & Specimen name & Column reinforcement & \multicolumn{3}{|l|}{ Beam reinforcement } \\
\cline { 4 - 5 } & & & Down & Up \\
\hline 1 & BW600 & $12 \varnothing 20$ & $3 \varnothing 14+2 \varnothing 16$ & $\mathbf{5 Ø 1 8}$ \\
\hline 2 & BW700 & $12 \varnothing 20$ & $3 \varnothing 14+2 \varnothing 16$ & $\mathbf{5 Ø 1 8}$ \\
\hline 3 & BW900 & $12 \varnothing 20$ & $3 \varnothing 14+4 \varnothing 16$ & $\mathbf{7 Ø 1 8}$ \\
\hline 4 & BW1000 & $12 \varnothing 20$ & $3 \varnothing 14+4 \varnothing 16$ & $\mathbf{7 Ø 1 8}$ \\
\hline
\end{tabular}




\section{A. FE model}

ABAQUS 6.13 software was used for analyzing the specimens by using finite element method. Having symmetric specimens, half models were simulated to decrease computational time. Loading and boundary conditions of the specimens are exactly similar to the experimental tests [3]. A lateral displacement of $150 \mathrm{~mm}$, which corresponds to a $5 \%$ drift for the $3 \mathrm{~m}$ columns, and an axial load of $230 \mathrm{kN}$ were applied on the top surface of the column. In accordance with the experimental study, both ends of the beam were restricted to move only through the beam axis as shown in Figure 2, and as such were vertically constrained. Elastic-linear plastic model was used to define mechanical properties of the steel reinforcement. The value of the elastic modulus and yield stress of the reinforcement as reported in experimental study was in the range of 195.7 $224.5 \mathrm{GPa}$ and 345 - $497 \mathrm{MPa}$, respectively. Ultimate stress of the reinforcement was $730 \mathrm{MPa}$ and ultimate strain was 0.51 . For the concrete, the elastic modulus, tensile strength and compressive strength were reported as 20.2 GPa, 2.68 MPa and 28.73 MPa, respectively. Concrete Damage Plasticity model was used to model concrete behavior subjected to lateral displacement. A 3 dimensional solid shape model using 3D Stress Hexahedral element type (C3D8R) was implemented to simulate concrete behavior. Wire shape model, in which truss elements (T3D2) were implemented, was used to simulate steel reinforcement behavior. The size of elements was refined several times in order to obtain a converged solution. Accordingly, 26433 C3D8R elements and 14300 T3D2 elements were defined as the most optimized number of elements for this FE model as shown in Figure 3.
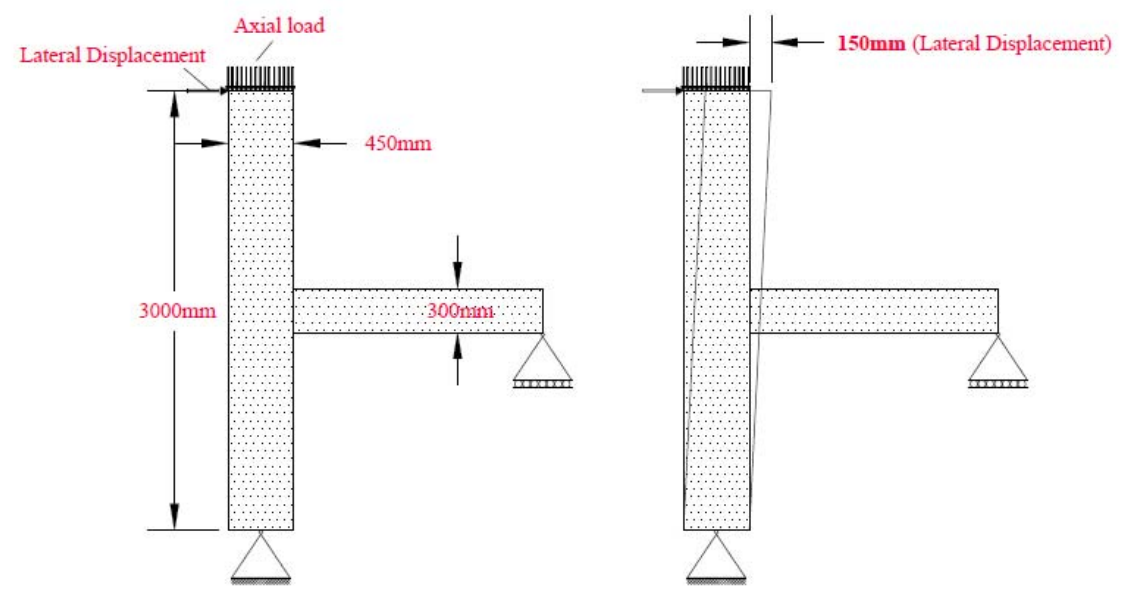

Fig. 2. Schematic view of the loading and constraints applied to FE model
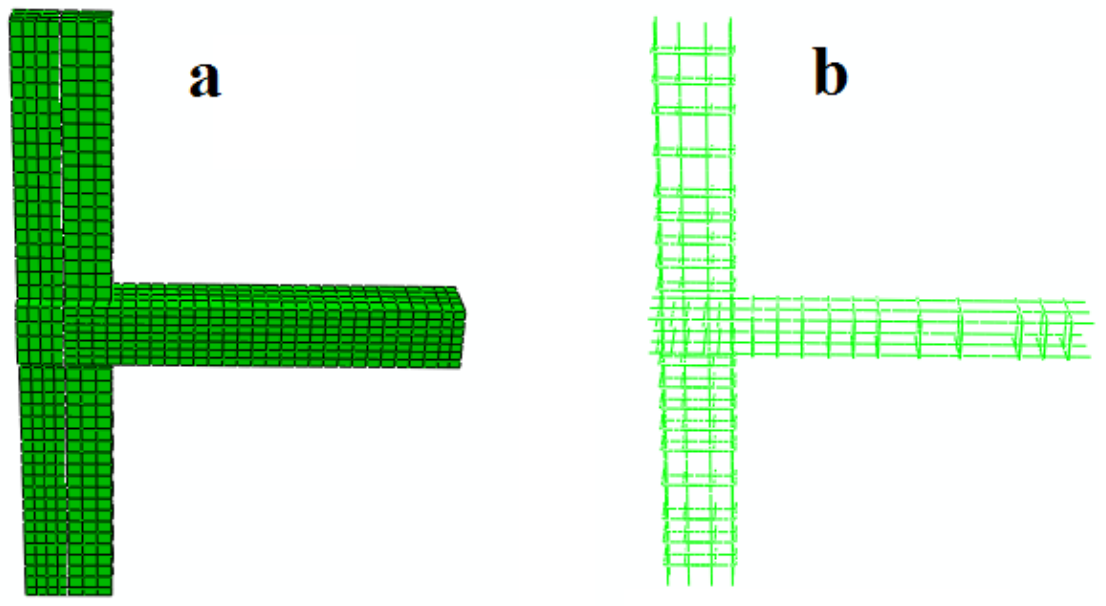

Fig. 3. Elements structure; (a) concrete (b) reinforcements

\section{B. Model Verification}

Figure 4 shows the graph of lateral load-horizontal drift of EWBCC specimen for experimental test conducted by Fadwa et al. [3]. The trace of the envelope behavior of EWBCC structure is compared with the force-displacement graph from the numerical model simulated by ABAQUS software and shown in Figure 5. 


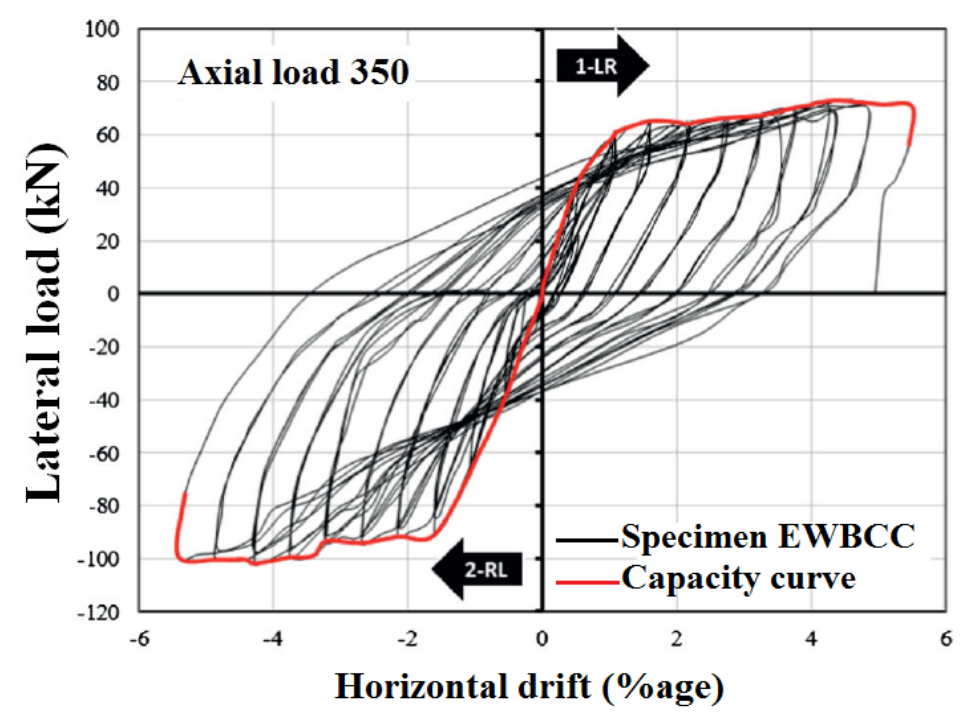

Fig.4. Lateral load versus drift ratio of experimental test

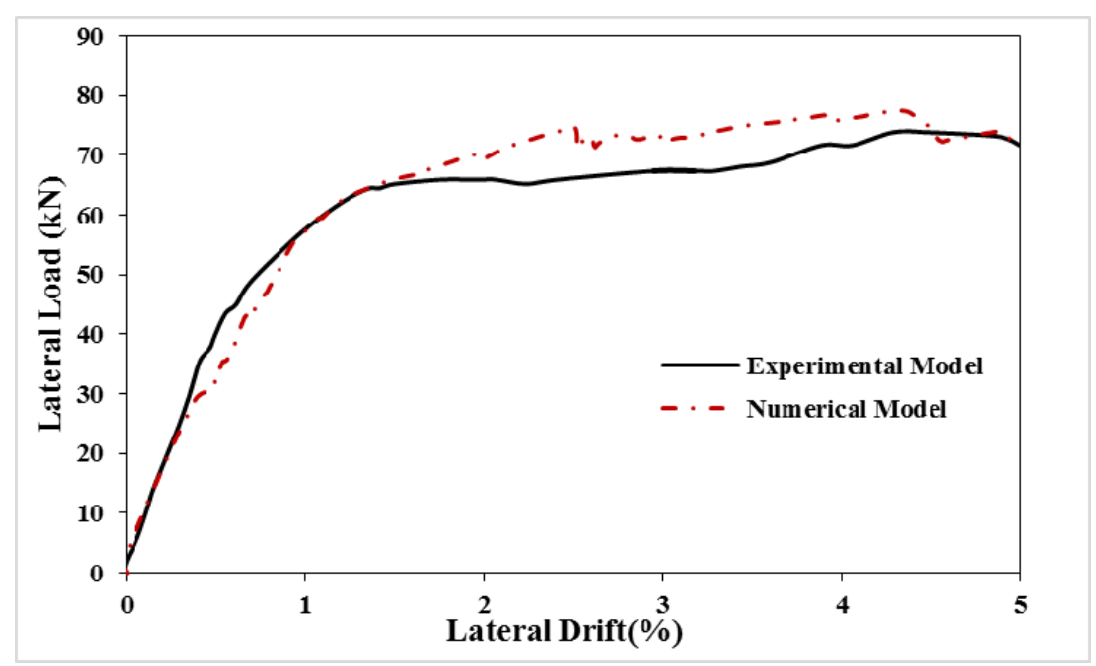

Fig.5. Verification of finite element model of BW900 results with experimental results

As can be seen in Figure 5, there is a close correlation between the force-displacement graphs of the FE simulation and experimental test which verifies the accuracy of the numerical model. The elastic phase of the FE model, which corresponds to a lateral load up to approximately $25 \mathrm{kN}$ shown in the Figure 5, shows very close agreement with the experimental model. Furthermore, the plastic phase shows good agreement with a maximum difference between experimental and numerical curves occurring at approximately 2.25 percent drift with only $11 \%$ difference. It is worth noting that the ultimate lateral drift experienced during the experimental testing is slightly above 5\%, as shown in Figure 4. The FE modeling simulated a lateral displacement of 150 $\mathrm{mm}$, which corresponds to a drift value of exactly $5 \%$, as shown in Figure 5.

\section{Mechanical properties}

\section{III.RESULTS AND DISCUSSION}

To determine the influence of varying beam width on mechanical parameters, including ductility and stress distribution, four models with various sizes of beam width (BW600, BW700, BW900 and BW1000) were simulated. The results of this simulation have been presented and investigated in the following sections.

Figures 6 and 7 demonstrate von Mises stress distribution of concrete and steel reinforcement respectively, for all four beam width configurations (i.e., BW600, BW700, BW900 and BW1000). The stress distributions are presented for an application of $150 \mathrm{~mm}$ of lateral displacement. 

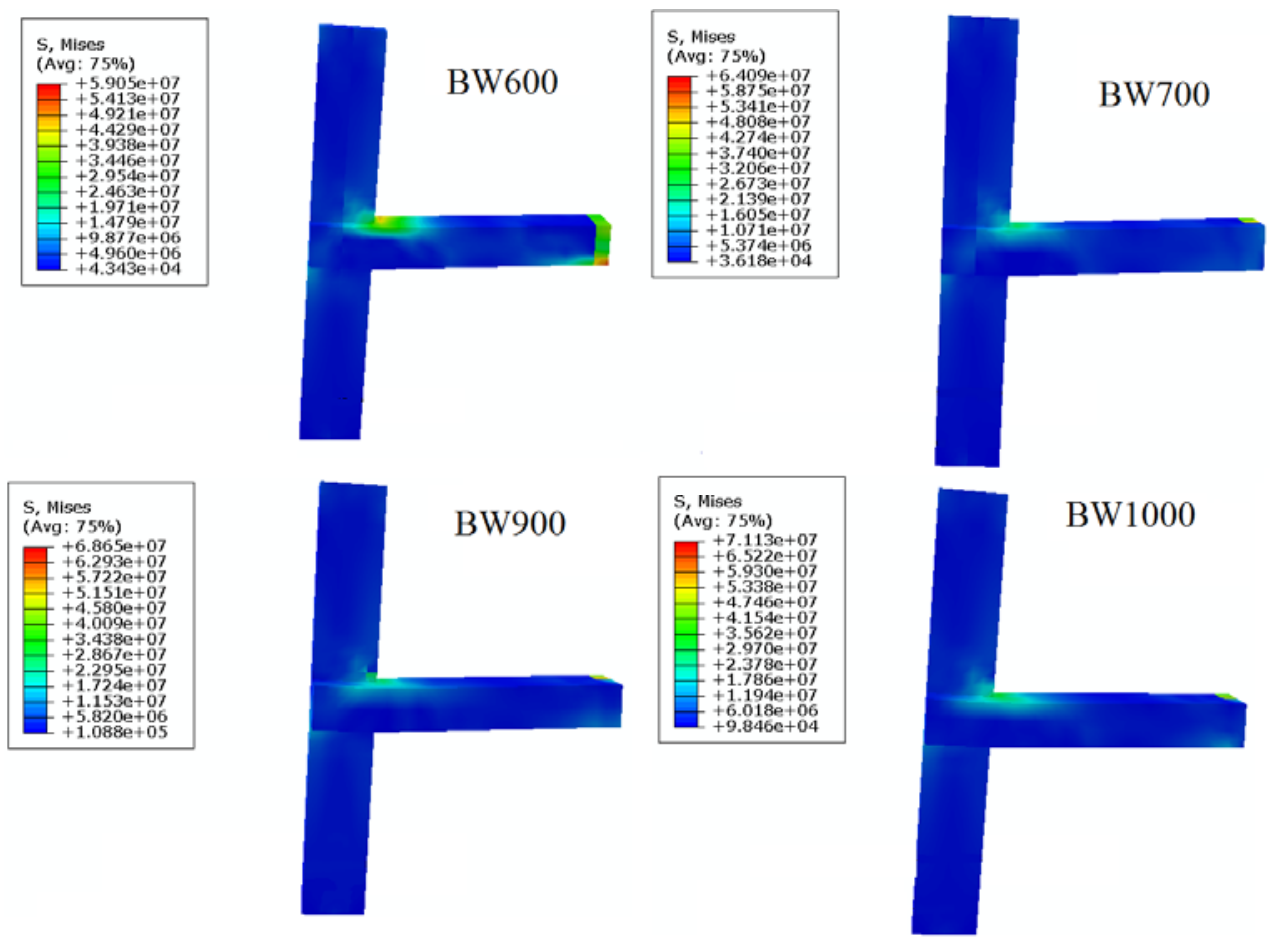

Fig. 6. Distribution of concrete stress in all beam width configuration

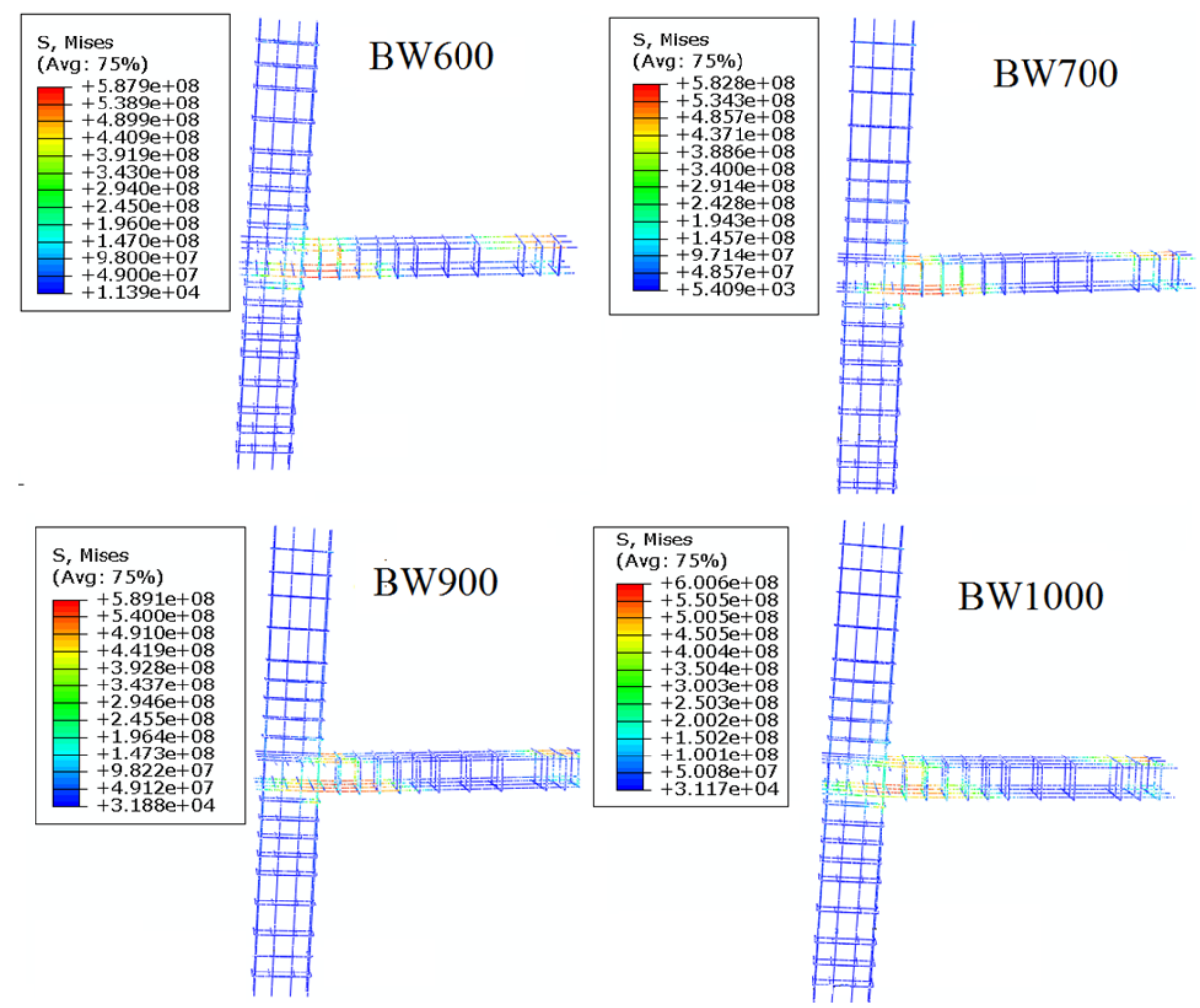

Fig. 7. Distribution of steel reinforcement stress in all beam width configurations

As expected, it can be seen in Figures 6 and 7 that the critical area of maximum stresses is located close to the beam-to-column connection. From Figure 6, it can be seen that the reported von Mises stresses for the concrete are 59, 64, 68 and $71 \mathrm{MPa}$ corresponding to BW600, BW700, BW900 and BW1000 specimens, respectively. Therefore, it can be concluded that by increasing the width of the beam, the von Mises stress will increase under the applied lateral displacement. This outcome indicates that increasing the beam's width can result in the local damages in EWBCC. It should be noted, Figure 6 demonstrates the stress distribution in concrete which is based 
on the Concrete Damage Plasticity model. In this figure, higher stress, in a specific area, shows a local damage in each structure, while the strength of the whole structure may be higher in comparison with other specimens. Moreover, it should be noted that the loading process is by displacement-control and higher forces are required in specimens with wider beams to achieve the $150 \mathrm{~mm}$ displacement which can lead to higher concrete stresses in connection areas.

Figure 7 shows that, as expected, the stresses developed in the steel reinforcement are much higher than those in the concrete. Maximum stress developed in the reinforcement for all specimens is approximately $600 \mathrm{MPa}$, which indicates yielding of the reinforcement bar occurred for all 4 specimens.

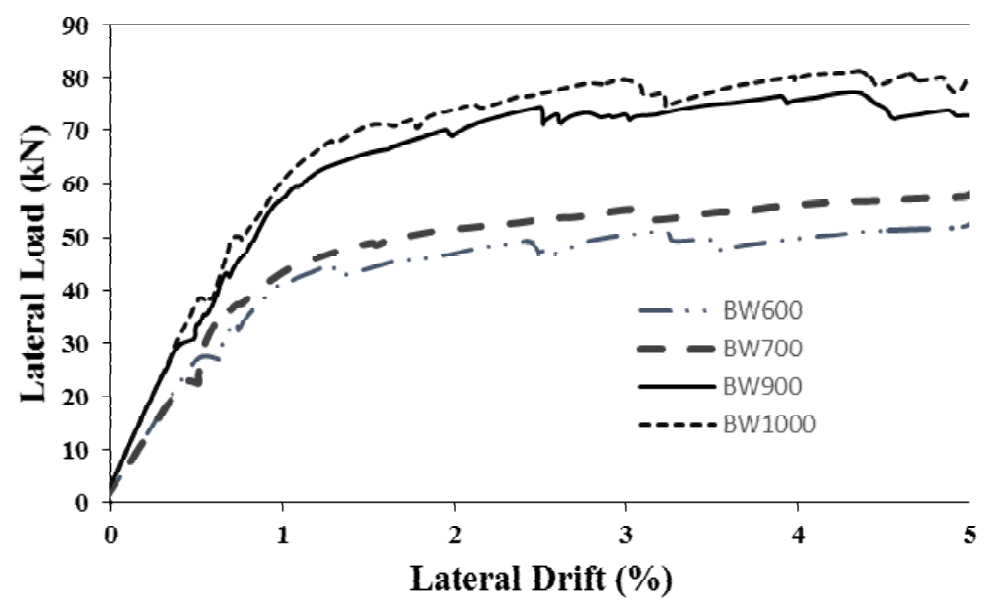

Fig.8. Force-displacement curves of all specimens

Figure 8 presents the force-displacement curves obtained from the FE simulation for all specimens of EWBCC. As can be seen in Figure 8, the value of the lateral loads is almost the same when comparing beams with similar reinforcement (i.e., comparing BW600 to BW700 and BW900 to BW1000) until 0.7\% drift which can be considered as the corresponding point in which plastic phase is initiated. Maximum tolerated lateral load of the BW600, BW700, BW900 and BW1000 specimens are 60,62, 76 and $81 \mathrm{kN}$, respectively. Therefore, it can be understood that in plastic phase the beams with widths of 900 and $1000 \mathrm{~mm}$ resist approximately $60 \%$ higher loads when compared to beams with widths of 600 and $700 \mathrm{~mm}$. It shows that the BW900 and BW1000 specimens can tolerate significantly more lateral force than others. This increase in lateral load can be attributed to the increase in steel reinforcement from $5 \varnothing 18$ to $7 \varnothing 18$ in top and $2 \varnothing 16$ to $4 \varnothing 16$ in bottom of beam as well as the increase in beam width.

According to the Fadwa's research [3], the yield strength was estimated as $0.75 \%$ of the ultimate strength, which was obtained from the force-displacement curves of the specimens and the displacement corresponded to the point of intersection of initial tangent stiffness with horizontal line at $0.75 \mathrm{Vu}$. Displacement ductility $(\mu \Delta)$ is defined by ultimate displacement divided by displacement corresponding to yield stress. Using this definition of yield strength the calculated yield strength for BW600, BW700, BW900 and BW1000 specimens are 45, 47, 57 and $61 \mathrm{kN}$, respectively. It can be understood that the yield strength of the models with the beam's width of 900 and $1000 \mathrm{~mm}$ is much higher compared with the models with the beam's width of 600 and $700 \mathrm{~mm}$. The value of the displacement ductility for BW600, BW700, BW900 and BW1000 specimens are 3, 2.8, 2.1 and 1.9, respectively. Therefore, it can be concluded that by increasing the width of the beam, the value of the yield displacement will be increased which has led to the decrease of ductility. Table 2 shows the comparison of mechanical properties between all specimens, where the performance of BW600 is used as a reference point. The beam height for all specimens was kept constant at $300 \mathrm{~mm}$ and the percentages strength increase and ductility decrease are summarized in Table 2 .

TABLE II. Comparison between Mechanical Properties of BW600 and Other Specimens

\begin{tabular}{|l|l|l|l|}
\hline Properties & BW700 & BW900 & BW1000 \\
\hline Increase in ultimate strength (\%) & $3.3 \%$ & $25.8 \%$ & $35.6 \%$ \\
\hline Increase in yield strength (\%) & $3.3 \%$ & $25.8 \%$ & $35.7 \%$ \\
\hline Decrease in ductility (\%) & $4.6 \%$ & $28 \%$ & $36.2 \%$ \\
\hline
\end{tabular}




\section{Energy Dissipation}

One of the most important parameters for structures designed to resist against earthquake loading is the capacity for energy dissipation. When structures are subjected to seismic loading, after passing elastic phase, they start to dissipate energy. Therefore, more dissipation of energy results in a decrease in damages experienced during an earthquake. Due to the importance of this parameter, researchers conducted several investigations into the ways to increase energy dissipation. In this study, the energy dissipation capabilities of the four specimens are compared. After analyzing the models by using finite element method, the curves of plastic energy dissipation were obtained from ABAQUS output data. Figure 9 (a) shows the graph of the plastic dissipated energy versus lateral drift for finite element models. It can be understood that by increasing beam width the amount of the energy dissipation increases. From this figure it can be easily understood that BW600 and BW700 have similar behavior throughout the curve, including the plastic zone. Moreover, at the lateral drift of $5 \%$ the dissipation energy for BW1000 is $33 \%$ more than that of in BW600. The value of the dissipation energy of BW900 is slightly smaller, but still comparable with BW1000. It is evident that the amount and configuration of steel reinforcement significantly influences the value of the dissipation energy. Figure 9 (b) demonstrates plastic dissipated energy versus applied force. It shows for the similarly reinforced BW600 and BW700, the amount of dissipation energy is similar, with this trend also evident when comparing the results for BW900 to BW1000. Furthermore, it can be understood from Figure 9 (b) that dissipation energy for all models is initiated at approximately $25 \mathrm{kN}$ during the aforementioned transition from elastic to plastic phase, however it can be seen that rapid development of dissipation energy occurs at approximately $40 \mathrm{kN}$ for all specimens.
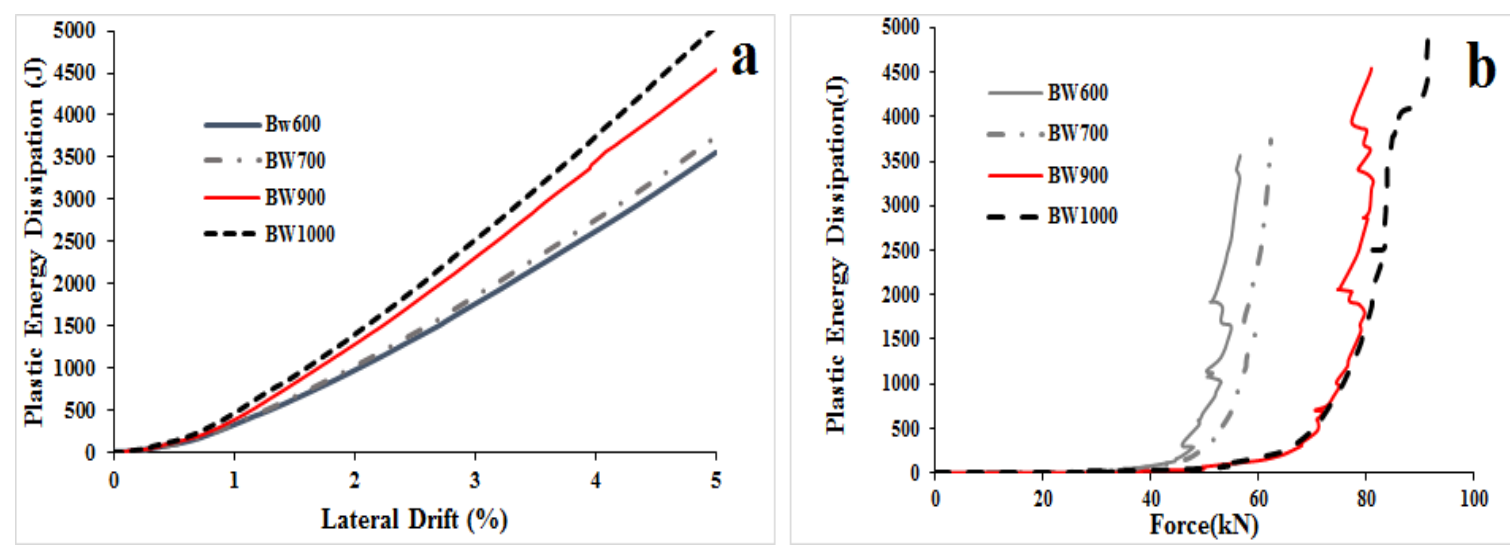

Fig. 9. Development of plastic energy dissipation (a) applied lateral drift (b) applied force

\section{E. The influence of axial load}

In this study, the influence of the column axial load on the behavior of exterior wide beam under lateral loading was investigated. As explained previously, analyses of axial loads smaller than $0.1 f_{c} A_{g}$ were considered. For this aim one of the exterior wide beam specimens (BW700) was subjected to axial loads of $0.029 f_{c} A_{g}, 0.04$ $f_{c} A_{g}$ and $0.068 f_{c} A_{g}$ which corresponds to axial loads of 150,230 and $350 \mathrm{kN}$. These values were chosen based on experimentally recorded data [3]. Figure 10 shows the effect of the axial load on the force-displacement graph for the BW700 specimen.

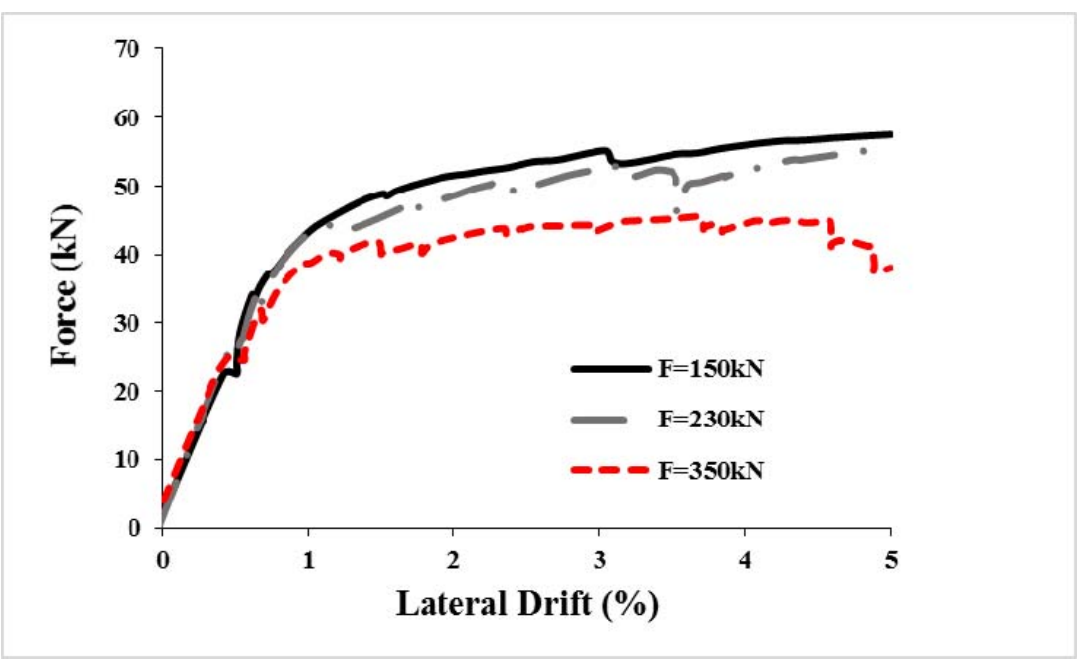

Fig. 10. Influence of axial load on behavior of BW700 model 
Figure 10 reveals that, in the elastic phase, column axial loading does not have a significant influence on the lateral behavior of the structure. However, in the plastic zone, increasing the column axial load can cause a reduction in strength. For example, at the drift of $5 \%$ the strength of the structure with $0.68 f_{c} A_{g}$ axial load is $30 \%$ lower than the strength of the structure with $0.029 f_{c} A_{g}$ axial load.

\section{IV.CONCLUSION}

This study has presented a computational investigation using finite element method to quantitatively evaluate the effect of beam width on the behavior of wide beam-column connections under lateral loading. Four configurations with beam widths of $600,700,900$ and $1000 \mathrm{~mm}$ were simulated. These models were exterior wide beam- column connections and the dimension and reinforcement details for columns in each model remained constant. The influence of varying the beam width on ductility, strength and plastic energy dissipation of the joints was studied. In addition to this, the effect of the amount of axial load applied on the column was evaluated.

- An increase in beam width results in a significant reduction in ductility of the beam-column joint against lateral loading. This outcome was observed for beam widths varying from 600 to $1000 \mathrm{~mm}$ which led to a maximum reduction in ductility of the structure by $36.2 \%$.

- Amount and configuration of reinforcement bars played an important role on strength of the specimens. So that, an increase in amount of reinforcement from $5 \varnothing 18$ to $7 \varnothing 18$ in top and $2 \varnothing 16$ to $4 \varnothing 16$ in bottom of beam has led to increase of $35.6 \%$ in strength.

- For wide beam specimens, an increase in width of beam will result in enhancement of energy dissipation. So that, a beam width increase from 600 to $1000 \mathrm{~mm}$ led to $33 \%$ increase in plastic energy dissipation.

- For axial loads smaller than $0.1 f_{c} A_{g}$ and creating an elastic force-displacement response, there was no significant influence caused by increasing the axial load. Whereas, in the plastic phase, an increase in the axial load results in a significant decrease in strength of the structure.

\section{REFERENCES}

[1] J.M. LaFave, "Behavior of Reinforced Concrete Exterior Wide Beam-Column-Slab Connections Subjected to Lateral Earthquake Loading," C. Eng. thesis, University of Michigan, Michigan, USA, Apr. 1997.

[2] B. Li, S. Kulkarni, "Seismic behavior of reinforced concrete exterior wide beam-column joints," Journal of Structural Engineering., vol. 136: pp. 26-36, Nov. 2010.

[3] I. Fadwa, A. Abbas Ali, E. Nazih, M. Sara, "Reinforced concrete wide and conventional beam-column connections subjected to lateral load," Engineering Structures., vol. 76, pp. 34-48, Jun. 2014.

[4] JS. Stehle, H. Goldsworthy, P. Mendis, "Reinforced concrete interior wide-band beam-column connections subjected to lateral earthquake loading," Structural Journal., vol. 98, pp. 270-279, Dec. 2001.

[5] WL. Siah, JS. Stehle, P. Mendis, H. Goldsworthy, "Interior wide beam connections subjected to lateral earthquake loading," Engineering Structures., vol. 25, pp. 281-291, Sep. 2003.

[6] T. Russell Gentry, K. Wight, "Wide beam - column connections under earthquake - type loading," Earthquake Spectra., vol. 10, pp.675-703, Nov. 1994..

[7] JM. LaFave, JK. Wight, "Reinforced concrete exterior wide beam-column-slab connections subjected to lateral earthquake loading," ACI Structural Journal., vol. 96, pp. 577-585, Nov. 1999.

[8] ACI318, Building Code requirements for structural concrete, Farmington Hills, Michigan, USA: American Concrete Institute, 1995.

[9] B. Li, S. Kulkarni, "Seismic behavior of reinforced concrete interior wide beam-column joints," Journal of Earthquake Engineering., vol. 13, pp. 80-99, Jul. 2008.

[10] AM. Elsouri, MH. Harajli, "Seismic response of exterior RC wide beam-narrow column joints: Earthquake-resistant versus as-built joints," Engineering Structures., vol. 57, pp. 394-405, May. 2013.

[11] AM. Elsouri, MH. Harajli, " Seismic response of exterior RC wide beam-narrow column joints: potential for improving seismic resistance," Engineering Structures., vol. 99, pp.42-55, Dec. 2015.

[12] D. Domínguez, F. López-Almansa, A. Benavent-Climent, "Would RC wide-beam buildings in Spain have survived Lorca earthquake (11-05-2011)," Engineering Structures., vol. 108, pp. 134-154, Jun. 2015.

[13] GM. Fernando, AD. Adolfo, DL. Flavia, M. Gerardo Verderame, "Seismic performances and behaviour factor of wide-beam and deepbeam RC frames," Engineering Structures., vol. 125, pp. 107-123, May. 2016.

[14] S. Mirzabagheri, AA. Tasnimi, SM. Mohammadi, "Behavior of interior RC wide and conventional beam-column roof joints under cyclic load," Engineering Structures., vol. 111, pp. 333-344, Sep. 2016.

[15] RP. Rodriguez, CQ. Febres, JF. Lopez, "Modeling of cyclic bond deterioration in RC beam-column connections," Engineering and Mechanics., vol. 26, pp.569-589. Nov. 2007

[16] S. Cho, SH. Sim, JW. Park, J. Lee, "Extension of indirect displacement estimation method using acceleration and strain to various types of beam structures," Smart Structures and Systems., vol.14, pp. 699-718. Apr. 2014.

[17] M. Unal, B. Burak, "Joint shear strengh prediction for reinforced concrete beam-to-column connections,"Structural Engineering and Mechanics., vol.41, pp. 421-440, Apr. 2012.

[18] S. Rajagopal, S. Prabavathy, HK. Kang, "Seismic behavior evaluation of exterior beam-coulmn joints with headed or hooked bars using nonlinear finite element analysis," Earthquak and Structures., vol. 7, pp. 861-875. Aug. 2014.

[19] B. Zoubek, Y. Fahjan, M. Fischinger, T. Isakovic, "Nonlinear finite element modelling of centric dowel connections in precast buildings," Computers and Concrete., vol. 14, pp. 463-477. Nov. 2014.

[20] MG. Kotsovou, E. Vougioukas, "Assessment of design methods for punching through numerical experiments," Computers and Concrete., vol. 17, pp. 305-322. Jun .2016.

[21] k. Mourad, G. Mohamed, "Numerical modelling of the damaging behaviour of the reinforced concrete structures by multi layers beams elements," Computers and Concrete., vol. 15, pp. 547-562. Jun. 2015. 
[22] K. Kitayama, S. Otani, H. Aoyama, "Development of design criteria for RC interior beam column joints," Design of beam-column joints for seismic resistance., vol. 123, pp. 97-123. Apr. 1991.

\section{AUTHOR PROFILE}

Elahe Etemadi*Corresponding author, email: E.etemadi.khosroshahi@gmail.com/ Department of Civil Engineering, Semnan University, Semnan, Iran. Tel: +61 420375505

Dr. Thomas Vincent, email: thomas.vincent@flinders.edu.au/ Lecturer in Structural Engineering, Faculty of Science and Engineering, School of Computer Science, Engineering and Mathematics, Flinders University, Adelaide, Australia 